\title{
Use of Plant-Based Fuels in Diesel Engines
}

\author{
Maxim Kulev*, Andrew Kulev, Natalya Kuleva, and Oleg Ivanov \\ Orel State University, 95 Komsomolskaya str., Orel, 302026, Russia
}

\begin{abstract}
One of the ways to reduce the consumption of oil-based liquid fuels and reduce air pollution is to increase the use of so-called nontraditional or alternative energy carriers in road transport. The most promising from this point of view are plant-based fuels.
\end{abstract}

\section{Introduction}

Currently, there are a large number of alternative energy sources suitable for use as fuel in ICE. The development of the Fuel and Energy Complex of Russia in particular and the country's economy as a whole will largely depend on the right choice of them. It is necessary to understand that even a slight increase in the cost of fuel can lead to a significant increase in prices for all consumer goods. In addition, it should be borne in mind that the current unfavorable environmental situation in the world is largely determined by the quality of the fuel used [1-5].

\section{Theory}

In connection with the deterioration of the environmental situation on the planet, the problem of using environmentally friendly fuel to power ICE becomes urgent. Comparative environmental characteristics of traditional and alternative fuels are presented in Table 1.

Biodiesel or bio-diesel fuel is an environmentally friendly type of fuel, an alternative to mineral types, derived from vegetable oils, and used to replace (save) conventional diesel fuel. The raw material for the production of biodiesel can be various vegetable oils: rapeseed, soybean, peanut, palm, used sunflower and olive oils (used, for example, in cooking), as well as animal fat [6-9].

Biodiesel can be used in conventional internal combustion engines, either alone or in a mixture with conventional diesel fuel [1].

Table 2 shows the physical and chemical properties of vegetable fuels compared to diesel fuel (DF): soybean oil (OS), palm oil (OP) and its esters Crude Palm Oil (CRO) and Crude Palm Stearin (CPS), sunflower oil (OSL), rapeseed oil (OR) and its esters (EMKOR) in internal combustion engines with compression ignition in steady-state operation.

\footnotetext{
* Corresponding author: maxim.ka@mail.ru
} 
Table 1. Comparative environmental characteristics of fuel

\begin{tabular}{|c|c|c|c|c|c|}
\hline Fuel Indicator & $\mathrm{CO} \%$ & $\mathrm{C}_{x} \mathrm{Hy}, \%$ & $\mathrm{NO}_{x}, \%$ & $\mathrm{CO}_{2}, \%$ & Soot, $\mathrm{mg} / \mathrm{m}^{3}$ \\
\hline Petrol & $0,5-12$ & $0,2-3,0$ & $0,01-0,8$ & $5,0-12$ & $0-100$ \\
\hline Diesel fuel & $0,01-0,4$ & $0,01-0,3$ & $0,004-0,5$ & $1,0-12$ & $0-2000$ \\
\hline Dimethyl ether & $1,0-24$ & $0,4-6$ & $0,004-0,5$ & $15-36$ & $0-200$ \\
\hline Methanol & $0,01-0,4$ & $0,01-0,3$ & $0,02-1,6$ & $1,0-12$ & $0-2000$ \\
\hline Ethanol & $0,01-0,4$ & $0,01-0,3$ & $0,004-0,5$ & $15-36$ & $0-2000$ \\
\hline Hydrogen & $2,0-48$ & $0,8-12$ & $0,03-2,4$ & $20-48$ & $0-400$ \\
\hline Electricity & $1,0-24$ & $0,4-6$ & $0,02-1,6$ & $1,0-24$ & $0-300$ \\
\hline Natural gas & $2,0-48$ & $0,8-12$ & $0,03-2,4$ & $15-36$ & $0-400$ \\
\hline Liquified Petroleum & $1,0-24$ & $0,4-6$ & $0,02-1,6$ & $15-36$ & $0-400$ \\
\hline Gas & - & $0,01-0,3$ & $0,002-0,3$ & - & $0-1860$ \\
\hline Plant-based fuels & & &
\end{tabular}

Table 2. Basic physical and chemical properties of plant-based fuels

\begin{tabular}{|c|c|c|c|c|c|c|c|c|c|c|c|}
\hline \multirow{2}{*}{ Parameter name } & \multicolumn{9}{|c|}{ Fuel grade } \\
\cline { 2 - 12 } & DF & OSL & OS & EMKOR & CPS & CPO & $\begin{array}{c}20 \% \\
\text { OR }\end{array}$ & $\begin{array}{c}4 \% \\
\text { OR }\end{array}$ & $\begin{array}{c}60 \% \\
\text { OR }\end{array}$ & $\begin{array}{c}80 \% \\
\text { OR }\end{array}$ & $\begin{array}{c}100 \% \\
\text { OR }\end{array}$ \\
\hline $\begin{array}{c}\text { Density at } 20^{\circ} \mathrm{C}, \\
\mathrm{kg} / \mathrm{m}^{3}\end{array}$ & 0,839 & 0,917 & 0,917 & 0,882 & 0,871 & 0,870 & 0,861 & 0,874 & 0,888 & 0,899 & 0,900 \\
\hline $\begin{array}{c}\text { Kinematic viscosity at } \\
40^{\circ} \mathrm{C}, \mathrm{mm}^{2} / \mathrm{s}\end{array}$ & 2,84 & 31,54 & 31,98 & 4,61 & 4,60 & 4,51 & 5,52 & 8,49 & 13,26 & 17,09 & 19,85 \\
\hline $\begin{array}{c}\text { Cetane number } \\
\text { Ignition Temperature, }{ }^{\circ} \mathrm{C}\end{array}$ & 40 & 250 & 250 & 130 & 165 & 174 & - & - & - & - & 200 \\
\hline $\begin{array}{c}\text { Calorific value, } \\
\text { MJ / kg }\end{array}$ & 43,84 & 37 & 38 & 36,7 & 39,8 & 40,1 & 43,12 & 41,97 & 40,38 & 39,53 & 37,10 \\
\hline $\begin{array}{c}\text { Surface tension, } \\
10^{-2} \mathrm{~N} / \mathrm{m}\end{array}$ & 3,71 & 3,22 & 3,22 & - & - & - & 3,59 & 3,52 & 3,44 & 3,39 & 3,38 \\
\hline
\end{tabular}

The physical properties of the fuel that affect the processes of mixture formation in the cylinders of the ICE include viscosity, surface tension and density. As the viscosity increases, 
the range of the fuel jet increases, which reduces the proportion of volumetric mixture formation and leads to more fuel hitting the walls of the combustion chamber. As the fuel viscosity decreases, the average diameter of the fuel droplets decreases and the spray becomes more uniform. However, the angle of dispersion of the fuel jet increases, and the range decreases. The higher the surface tension, the more resistant the drop is to external forces and the larger its size. The lower the surface tension, the thinner and more uniform the fuel atomization, which helps to accelerate the processes of mixture formation and combustion [1].

The most similar to diesel fuel in its physical and chemical properties is rapeseed oil. Therefore, when using it, the change in the design of the engine power system will be less significant compared to other alternative fuels.

To ensure the operation of the engine on biofuel, it is necessary to change the design of the power system elements or to bring the values of the state parameters of the fuel used to the values of diesel fuel. Changing the design of the power system will lead to additional costs for re-equipment of the engine. Therefore, it is more rational to reduce the density and viscosity of the fuel.

Fuel density is inversely proportional to its temperature:

$$
\rho=\rho_{0} /\left(1+\beta_{T} \Delta T\right)
$$

where $\rho_{0}$ is density at initial temperature $T_{0}, \mathrm{~kg} / \mathrm{m}^{3}$;

$\beta_{T}$ is the volumetric expansion coefficient, which is the relative change in volume with a change in temperature $T$ by $1^{\circ} \mathrm{C}$ and constant pressure, degrees ${ }^{-1}$. For mineral oils in the pressure range from 0 to $15 \mathrm{MPa} \beta_{T}$ can be taken on average equal to $800 \cdot 10^{-6}$ degree $^{-1}[1]$.

$\Delta T$ is temperature change, ${ }^{\circ} \mathrm{C}$.

$$
\Delta T=T-T_{0}
$$

$T$ is initial temperature, ${ }^{\circ} \mathrm{C}$;

$T_{0}$ is final temperature, ${ }^{\circ} \mathrm{C}$.

Then, taking into account Formulas (1) and (2), we get:

$$
T=\frac{\rho_{0}-\rho}{\rho \beta_{T}}+T_{0} .
$$

The viscosity of droplet liquids depends on the temperature and decreases with increasing temperature. The effect of temperature on the viscosity of liquids can be estimated by the Formula:

$$
\mu=\mu_{0} e^{-\beta\left(T-T_{0}\right)},
$$

where $\mu$ is the viscosity at the final temperature, $\mathrm{Pa} \cdot \mathrm{s}$;

$\mu_{0}$ is viscosity at the initial temperature, $\mathrm{Pa} \cdot \mathrm{s}$;

$\beta$ is the coefficient, the value of which for oils varies within the range of $0.02-0.03$.

Taking into account Formula (4), the temperature value required to obtain a given viscosity will be determined by the expression:

$$
T=\beta \ln \left(\frac{\mu_{0}}{\mu}\right)+T_{0} .
$$


Therefore, to reduce the viscosity and density of biofuel, it is necessary to introduce an additional structural element of the power system, a heater.

Figures 1 and 2 show the results of calculating temperatures to obtain the given values of density and dynamic viscosity of biofuel. The setpoints are determined by the properties of the diesel fuel.

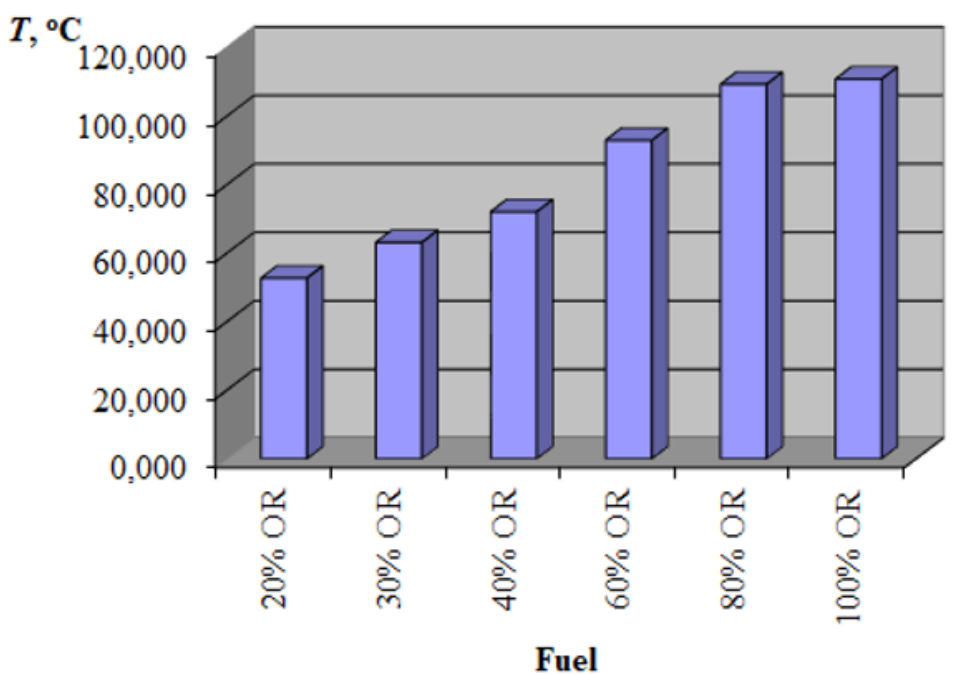

Fig. 1. Temperature values providing a biofuel density of $0.839 \mathrm{~kg} / \mathrm{m}^{3}$.

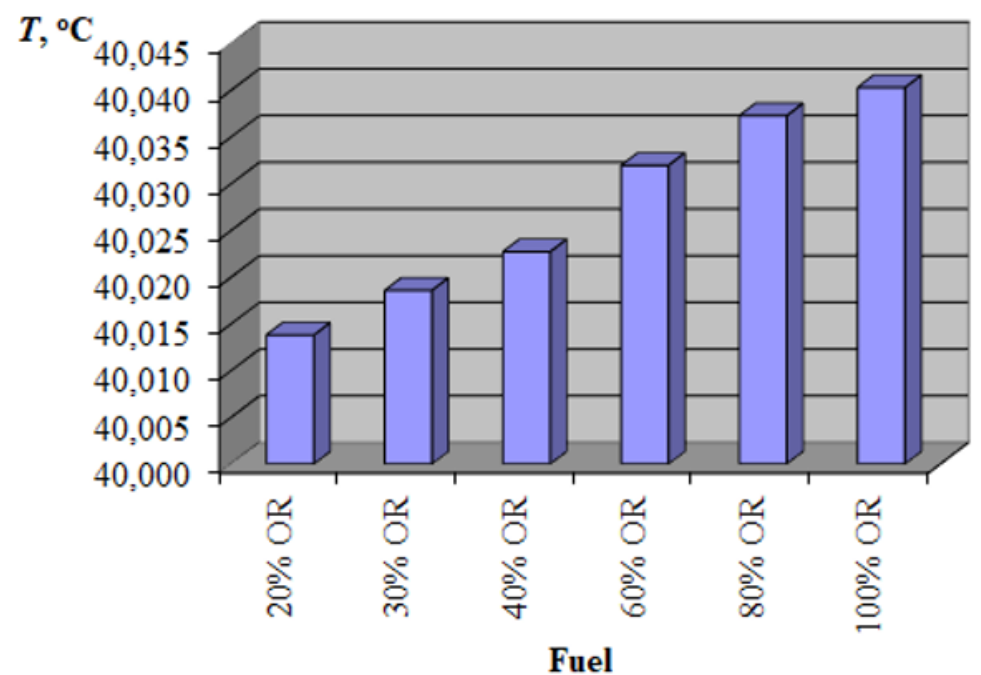

Fig. 2. Temperature values providing biofuel viscosity of 2,345 $\mathrm{Pa} \cdot \mathrm{s}$.

Analyzing the obtained values, we can conclude that an increase in the percentage of rapeseed oil in the composition of biofuel leads to an increase in the heating temperature required maintaining the specified values of density and dynamic viscosity of the fuel.

To ensure the working capacity of the engine power supply system with biodiesel fuel based on rapeseed oil, it is necessary to introduce additional structural elements: a fuel tank, a fuel heater and a fuel distribution valve. 
The block diagram of KamAZ-53212 truck engine feed system with biodiesel based on rapeseed oil is shown in Figure 3.

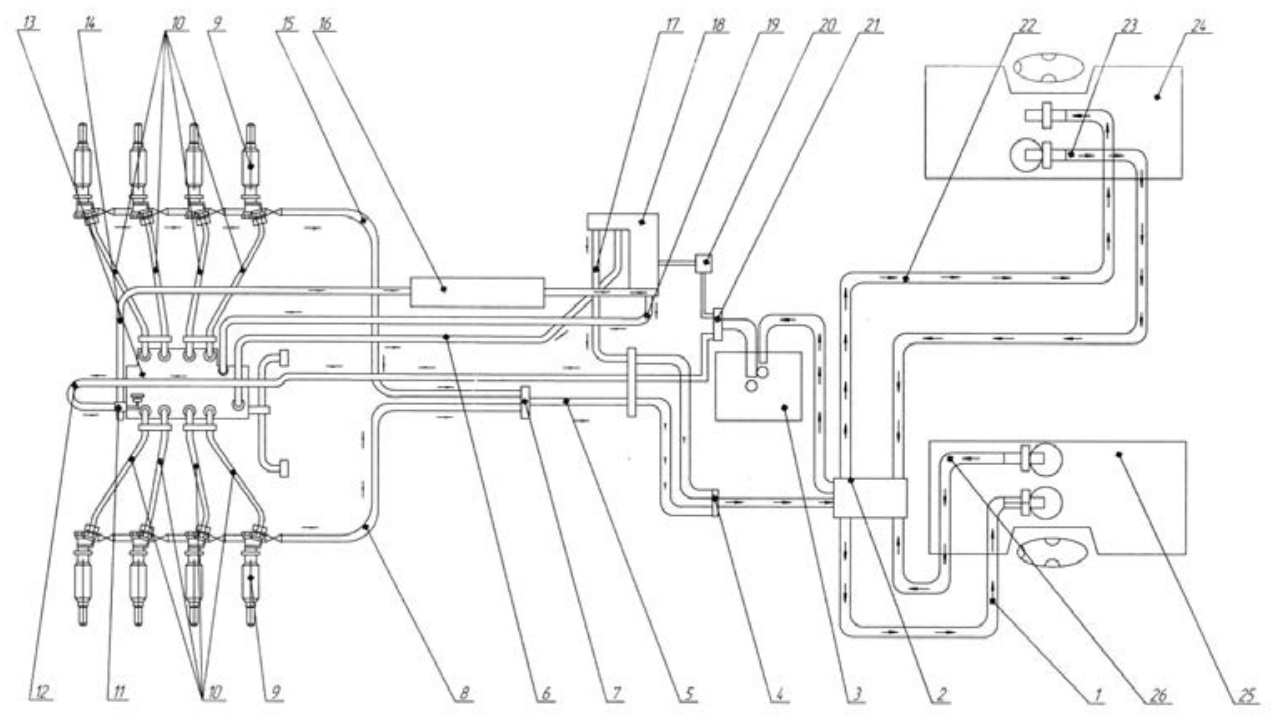

Fig. 3. Block diagram of KamAZ-53212 truck engine feed system with biodiesel based on rapeseed oil: 1, 5, 6, 8, 10, 12, 14, 15, 17, 19, 22, 23, 26 - fuel lines; 2 - fuel distribution valve; 3 fuel coarse filter; 4, 7, 21 - T-connector; 9 - injectors; 11 - fuel pump with manual and mechanical drives; 13 - high-pressure fuel pump; 16 - heat exchanger; 18 - fuel fine filter;20 - fuel pump with manual drive; 24 - fuel tank with plant-based fuel; 25 - fuel tank with diesel fuel.

\section{The conclusion}

The closest to diesel fuel in its physical and mechanical properties is rapeseed oil. The only drawback of biofuel is its high density, which is the main indicator that affects the working capacity of the power system elements. This disadvantage can be eliminated by heating the fuel. In general, the use of rapeseed oil as a fuel ensures minimal changes in the design of the engine power system. In addition, the use of biofuels results in an increase in torque and effective engine power. At the same time, the fuel consumption per hour increases slightly. Therefore, the use of rapeseed oil for powering an internal combustion engine is promising.

\section{References}

1. V. Lyotko, Application of alternative fuels in internal combustion engines / V. Lyotko, V. N. Lukanin, A. S. Khachiyan; ed. by V. Lyotko, V. N. Lukanin. - Moscow: MADI TU - 310 p. (2000)

2. A. Khairullin, V. Gureev, R. Salakhov, I. Salakhov, A. Zonov, Study of technical, economic and environmental indicators of diesel engines operating on mixed biofuels of plant origin. Bulletin of the Kazan State Technical University named after A. N. Tupolev. No. 4. pp. 65-67. (2014) 
3. K. Popov, A. Yunusov, R. Kashapov, V. Nikishin, Investigation of the efficiency of biofuel use in diesel engines. In the collection: Topical issues of technical sciences. Materials of the III International Scientific Conference. pp. 97-99. (2015)

4. V. Markov, S. Devyanin, A. Savastenko, Organization of diesel engine operation on mixed biofuel of variable composition. Proceedings of the Volgograd State Technical University. No. 18 (145). pp. 35-39. (2014)

5. A. Mezentsev. Physico-chemical bases of biofuels. Textbook / A. Mezentsev. St. Petersburg, 111 p. (2008)

6. M. Suresh, C.P. Jawahar, R. Rohith Renish, and A. Malmquist, Performance Evaluation and Emission Characteristics of Variable Compression Ratio Diesel Engine Using Argemone Mexicana Biodiesel. Energy Sources, Part A: Recovery, Utilization, and Environmental Effects 43, No. 12. pp. 1511-1523. (2019)

7. F. Weiliang, S. Wang, X. Duan, W. Wang, F. Yang, J. Xiong, T. Wang, and C. Wang. A Novel Approach for Enhancing Lipid Recovery for Biodiesel Production from Wet Energy Biomass Using Surfactants-Assisted Extraction” Renewable Energy No. 170. pp. 462-470. (2021)

8. S. Alireza, S. Bagherzadeh, G. Najafi, R. Mamat, and M. Mazlan. Optimization and Investigation the Effects of Using Biodiesel-Ethanol Blends on the Performance and Emission Characteristics of a Diesel Engine by Genetic Algorithm. Fuel No. 289. (2021)

9. S. Kumar, R. Kuppusamy, and P. Krishnan. Effect of Nanoparticle-Blended Biodiesel Mixtures on Diesel Engine Performance, Emission, and Combustion Characteristics. Environmental Science and Pollution Research (2021) 